\title{
Effect of soil type on nail pull-out resistance
}

Amir Shahraki Ghadimi MSc, CEng

Research Student, Faculty of Engineering, Kharazmi University, Tehran, Iran (corresponding author: Amir.shahraki1989@gmail.com)

Ali Ghanbari Phd, CEng

Professor, Faculty of Engineering, Kharazmi University, Tehran, Iran
Mohsen Sabermahani Phd, CEng

Assistant Professor, School of Civil Engineering, Iran University of Science and Technology (IUST), Narmak, Tehran, Iran

Mahmoud Yazdani Phd, CEng

Assistant Professor, Department of Civil and Environmental Engineering,

Tarbiat Modares University, Tehran, Iran

Nowadays, soil nailing is widely used to stabilize slopes and excavations. The bond strength is integrated shear strength along the interface area between grout and soil. Choosing a value for bond resistance is one of the effective parameters in nailed wall design, which is generally determined by the values proposed by FHWA guidelines. A designer uses a high safety factor that makes the design safe but sometimes it is not economical. Therefore, in this study, an attempt is made to investigate the effects of overburden, injection pressure and soil strength parameters on the bond strength of nails in field. For this research, five different sites in Tehran were considered with a total number of $\mathbf{2 0}$ soil-nail pull-out test. Values such as cohesion, friction angle, modulus of elasticity, moisture content, percentage of coarse- and fine-grained soil were determined in the laboratory, and the effect of these parameters on the bond strength was examined. The results of the tests showed that by increasing injection pressure and overburden height, bond strength increases, and that the effect of injection pressure is much more than that of overburden height. Finally, a relationship was suggested to estimate the bond strength in terms of soil specifications and overburden height.

\section{Introduction}

Nailing is a stabilisation system in excavations and slope surfaces. The main reasons for using this system are: $(a)$ short constructing period, $(b)$ it does not require a lot of equipment and $(c)$ cost-effective implementation (Chu and Yin, 2005; Schlosser, 1982). Nailing was used for the first time in 1980 in Hong Kong to stabilise trenches and slope surfaces. Using this method increases the general shear strength of soil, which leads to limited displacements in the excavation walls and slopes. A soil-nailed wall consists of a number of steel bars (with typical diameter of 25-40 mm) within a drilled borehole (generally with a diameter of $100 \mathrm{~mm}$ and length of 4-20 m) with cement grout (usually water-cement ratio 0.42) (Chu and Yin, 2005; Junaideen et al., 2004). Bond strength is integrated shear strength along the interface area between grout and soil. Bond strength is rarely measured in the laboratory and no standard for laboratory tests can be used to evaluate the bond strength ( $\mathrm{Su}, 2006$; Yin and $\mathrm{Su}, 2006$ ), so only a pull-out test in the field can provide a credible estimation of bond strength. Bond strength depends on a variety of factors such as environmental conditions, the nature of grout, injection type, overburden pressure and so on.

Su et al. (2008) preformed a series of laboratory pull-out tests on samples of completely decomposed granite (CDG) in order to evaluate the effect of overburden. These researchers found that increasing the stresses caused by overburden did not affect the pull-out resistance of gravity-injected soil-nail. This is due to the release of stress during the drilling process $(\mathrm{Su}$ et al., 2008). Su et al. (2008) carried out a series of pull-out tests on a sample of CDG soil and concluded that increasing the injection pressure leads to an increase in pull-out resistance. Zhou et al. (2008) found that the effect of injection pressure in samples injected under $200 \mathrm{kPa}$ pressure is much more than the effect of injection pressure in samples injected under $80 \mathrm{kPa}$ pressure. Also Su et al. (2007) carried out a series of laboratory tests on soils with saturation degrees of $38,50,75$ and $90 \%$ to evaluate the effect of saturation. These researchers found that by increasing the saturation of soil, shear surfaces locate some distance from the nail-soil surface during pull-out tests. Therefore, in dry soil, the shear resistance of the soil-nail interface and surrounding soil is less than the shear strength of the soil. These researchers also, by experimental investigation of pull-out testing in CDG soil, found that dense samples are fractured under the influence of shearing.

In this study, the bond strength of soil is evaluated in the form of a field study. Five test sites in Tehran were considered, which included 20 samples of soil-nails. Values such as cohesion, friction angle, modulus of elasticity, moisture content and percentage of coarse- and fine-grained soils were determined in the laboratory, and the effect of these parameters on the bond strength is examined.

\section{An introduction to the study area}

North and north-west of Tehran are the regions in which several deep excavations occur to a depth of over $30 \mathrm{~m}$ every year. Therefore, in this study, pull-out tests of soil-nails in five different areas of Tehran have been carried out. Five excavation projects were examined, starting from the beginning of excavation to the end of the project. Tehran's alluvial deposits can be divided into four formation parts named A, B, C and D. Part A is the oldest formation and part D is the newest formation. In order to evaluate the bond strength between soil and grout, five sites located in Kashani street, Saadat Abad, 

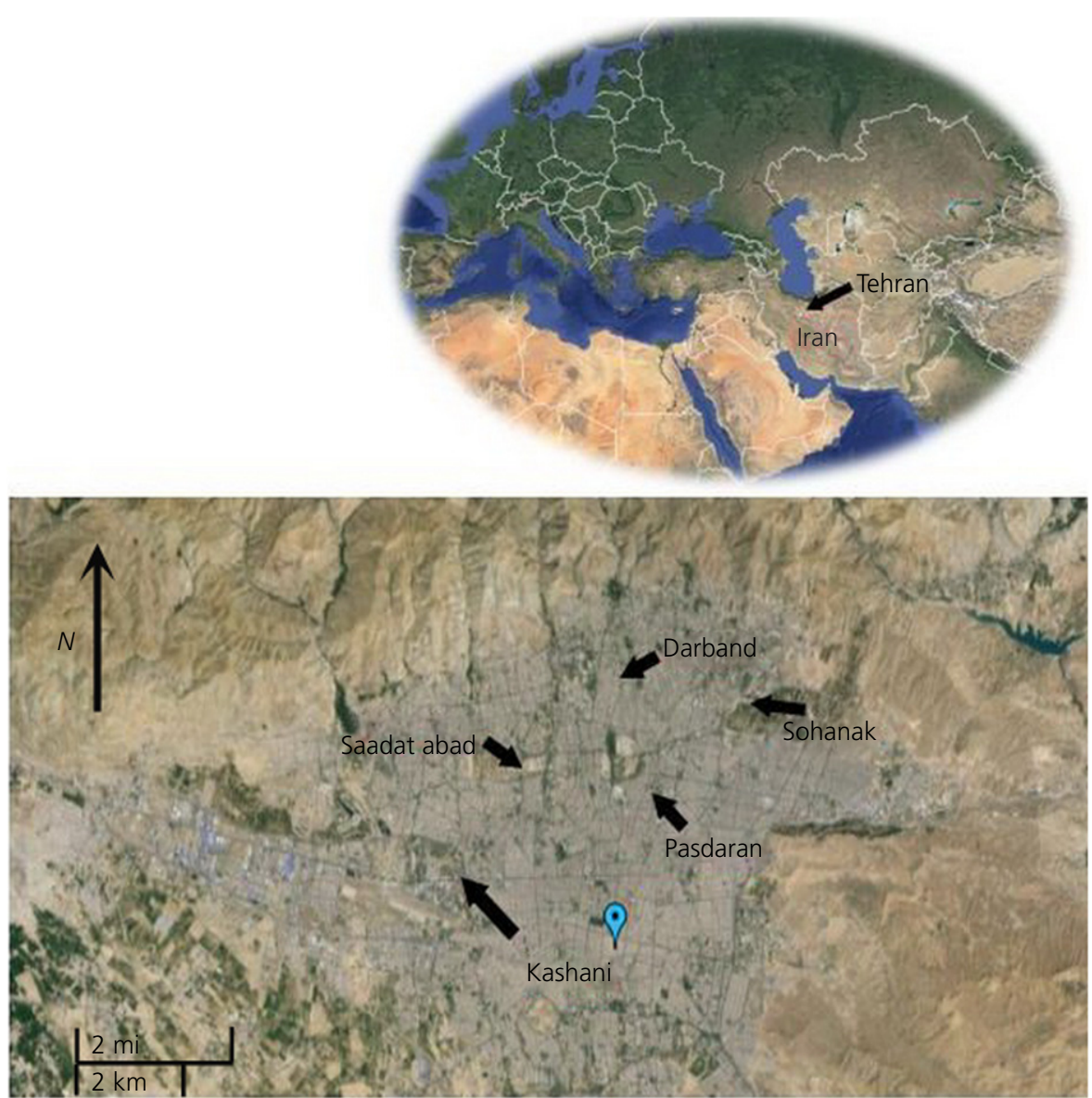

Figure 1. Position of test sites in this research

Table 1. Number of tests performed

\begin{tabular}{|c|c|c|c|c|c|c|}
\hline \multirow[b]{2}{*}{ Site name } & \multicolumn{3}{|c|}{ Field test } & \multicolumn{3}{|c|}{ Laboratory test } \\
\hline & In-situ direct shear test & Pull-out test & Plate load test & Atterberg limits & Moisture content & Soil gradation \\
\hline Darband & 6 & 4 & 2 & 3 & 3 & 1 \\
\hline Sohanak & 12 & 4 & 4 & 3 & 3 & 1 \\
\hline Pasdaran & 9 & 4 & 3 & 3 & 3 & 1 \\
\hline Kashani & 12 & 4 & 4 & 3 & 3 & 1 \\
\hline Saadat Abad & 6 & 4 & 2 & 3 & 3 & 1 \\
\hline
\end{tabular}

Darband, Sohanak and Pasdaran, which are indicated on the map provided in Figure 1 were studied. By examining the site locations, it is determined that Kashani site is located at $\mathrm{C}$ formation, Saadat Abad site is at B formation and three Pasdaran, Darband and Sohanak sites are at A formation.

\section{Experiments conducted}

To determine the parameters needed in this research, field and laboratory tests have been done on soil and soil nails. In Table 1, the number of field and laboratory experiments conducted in this study are shown.

\subsection{Laboratory tests}

To identify and acquire the technical and mechanical properties of subsurface materials, physical and mechanical tests were conducted in the laboratory on samples taken from the galleries in all test sites. Also disturbed samples were used to determine soil physical properties such as particle size distribution. Laboratory tests were carried out according to ASTM D 422-63 (1990). Physical properties in this study were determined using laboratory tests to establish the basic characteristics of the soil; these were conducted at the Geotechnical Laboratory in Kharazmi University of Tehran. 
Table 2. The physical properties of studied soils

\begin{tabular}{|c|c|c|c|c|c|c|c|}
\hline & \multirow[b]{2}{*}{ Moisture content } & \multicolumn{3}{|c|}{ Atterberg limits } & \multicolumn{3}{|c|}{ Soil gradation } \\
\hline & & $\mathrm{PI}$ & PL & LL & Gravel content & Sand content & Fine content \\
\hline Saadat Abad & $9 \cdot 24$ & $14 \cdot 9$ & $19 \cdot 8$ & $34 \cdot 7$ & $44 \cdot 42$ & $49 \cdot 3$ & $6 \cdot 27$ \\
\hline Kashani & $7 \cdot 6$ & 4 & $19 \cdot 8$ & $23 \cdot 8$ & $38 \cdot 3$ & $57 \cdot 16$ & 4.53 \\
\hline Sohanak & $7 \cdot 4$ & 14.43 & $25 \cdot 75$ & 40 & 38.02 & $54 \cdot 51$ & $7 \cdot 46$ \\
\hline Pasdaran & $10 \cdot 54$ & $6 \cdot 6$ & $17 \cdot 2$ & $23 \cdot 8$ & $42 \cdot 79$ & $49 \cdot 68$ & $7 \cdot 52$ \\
\hline Darband & $9 \cdot 52$ & $7 \cdot 5$ & 18 & $25 \cdot 5$ & $37 \cdot 86$ & 56.94 & $5 \cdot 19$ \\
\hline
\end{tabular}

PI, plasticity index; PL, plastic limit; LL, liquid limit

Table 3. Soil strength properties of various sites

\begin{tabular}{lccccc} 
& \multicolumn{2}{c}{ Soil parameters } & & \multicolumn{2}{c}{$\begin{array}{c}\text { Parameters of shear } \\
\text { strength of soil }\end{array}$} \\
\cline { 2 - 3 } & $E: \mathrm{kN} / \mathrm{m}^{2}$ & $\gamma: \mathrm{kN} / \mathrm{m}^{3}$ & & $\Phi:$ deg & $\mathrm{C}: \mathrm{kN} / \mathrm{m}^{2}$ \\
Saadat Abad & 65000 & $20 \cdot 2$ & & 33 & 7 \\
Kashani & 80000 & 21 & & 38 & 12 \\
Sohanak & 35000 & 20 & & 33 & 49 \\
Pasdaran $(H=5)$ & 35000 & 20 & & 45 & 2 \\
Pasdaran $(H=20)$ & 48000 & 20 & & 45 & 1 \\
Darband & 60000 & $20 \cdot 6$ & & 35 & 9
\end{tabular}

\subsection{Field tests}

The strength properties examined in this study include the parameters of shear strength, modulus of elasticity and soil density, which were estimated by plate load test, pull-out test and in situ direct shear tests. Physical properties and resistance information of the studied soil are shown in Tables 2 and 3, respectively. It should be noted that the high value of soil cohesion in the Sohanak site is due to a high degree of soil cementation.

\section{Pull-out test}

According to a Federal Highway Administration (FHWA) report, at least two destructive tests must be done in each layer of soil (Lazarte et al., 2003). This test was performed on nonstructural soil-nails (sacrifice) before installing structural soilnails in order to assess the drilling method and review the resistance required for soil-nails. In this experiment, a part of the nail bar is not injected, of at least $1 \mathrm{~m}$ length. The bonded soil nail length during verification tests is at least $3 \mathrm{~m}$, but it should not exceed the maximum length. In fact, the maximum effective length is achieved when the release strength of a soilnail equals $90 \%$ of the allowable tensile strength of the nail bar Lazarte et al. (2003).

\subsection{Sample preparation}

Drilling operations are done in two levels of +4 and $+8 \mathrm{~m}$. The diameter of the bar used in this test is $40 \mathrm{~mm}$ and its properties are shown in Table 4. According to a FHWA report, the maximum tolerable force in the tensile test is $0 \cdot 9 f_{\mathrm{y}} \times A$ (Lazarte et al. (2003)) where $f_{\mathrm{y}}$ is yield stress and $A$ is the cross-sectional area of the bar. Also covered length and free
Table 4. Bar specifications

$\begin{array}{ll}\text { Bar specifications tested } & \\ f_{\mathrm{y}} \text { (yield stress) } & 4000 \mathrm{~kg} / \mathrm{cm}^{2} \\ A_{\mathrm{y}} \text { (cross-section area) } & 12 \cdot 60 \mathrm{~cm}^{2} \\ E \text { (modulus of elasticity) } & 12 \mathrm{GPa} \\ 0.9 f_{\mathrm{y}} \times A \text { (maximum tolerable tensile force) } & 55000 \mathrm{~kg}\end{array}$

length are considered to be 3 and $1 \mathrm{~m}$, respectively. The rotary drilling method was utilised and, in each level, two bars were embedded. One of them was injected according to the gravityinjected mode and another was injected at $200 \mathrm{kPa}$ pressure.

\subsection{Test procedure}

According to a FHWA report, a period of $7 \mathrm{~d}$ is needed to reach the desired strength after drilling and grout injection, and then the sample is prepared for testing. In order to perform the test, an Enerpac $600 \mathrm{kN}$ cylindrical hydraulic jack was used. The pressure gauge is calibrated according to ISO 143904-Ukas (England) (Ukas, 2006). As shown in Figure 2, the components of the jack are

- displacement gauge

- pressure gauge

hydraulic lever pump

- cylindrical jack

- hydraulic hoses

To perform tests according to Ukas (2006), the test was carried out with constant force with 10 min rest time. At each stage of the experiment, the value of force increment was $50 \mathrm{kN}$. In Table 5, a sample of collected information is given for each experiment where $q_{\mathrm{u}}$ is the bond strength of the soil.

\section{Pull-out test results}

In this section, investigation and interpretation of pull-out tests results were carried out. As shown in Table 2, soils in all sites have a fine-grained percentage of $<10$, therefore the properties of soil plasticity are not considered. Also, considering the low groundwater levels at all sites, soil moisture changes do not affect the results. Therefore, in all soils the moisture content is assumed to be the same and an attempt is made to investigate the effect of other parameters on the bond strength. 
Effect of soil type on nail pull-out resistance

Shahraki Ghadimi, Ghanbari, Sabermahani

and Yazdani

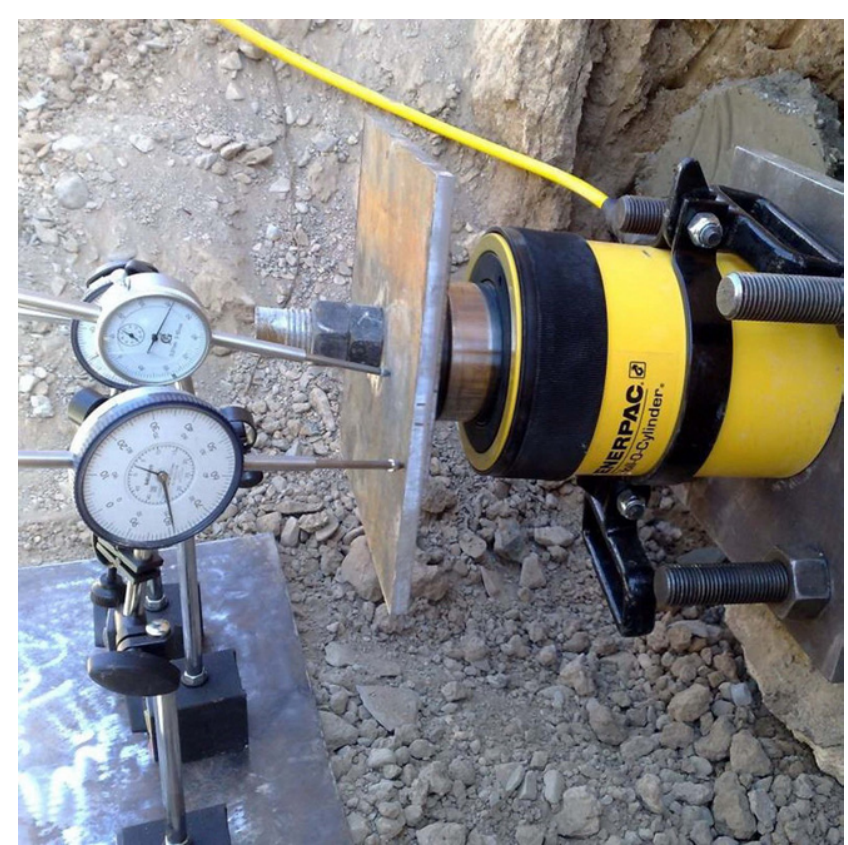

Figure 2. Components of Enerpac jack used in the experiments of this study

\subsection{Determination of bond strength}

In Figure 3, the load-time curve is plotted for a nail; it can be seen that, by increasing the time, the value of force increases and, after reaching a maximum value, it is reduced. By using a load-time graph, the bond strength of grout for gravityinjected and soil nails injected under pressure can be examined. Finally, the cohesion strength of grout and soil is determined.

\subsection{Examining pull-out resistance against displacement}

As shown in Figures 4-8, generally the maximum pull-out resistance is related to soil-nails injected under $200 \mathrm{kPa}$ pressure, which are installed at a level of $8 \mathrm{~m}$. The minimum pull-out resistance is related to gravity-injected soil-nails that are installed at a level of $4 \mathrm{~m}$. It is also found that the pull-out resistance increased with increasing injection pressure and height of soil overburden. The nature of the increment suggests that the influence of injection pressure is much greater than the influence of height pressure due to overburden soil.

From the review of the Sohanak site (Figure 7) the authors found that the process of displacement changes among four soil-nails were very closely aligned. The reason for this phenomenon can be explained according to the cementation and reduction in the spaces between soil grains. Also by examining Figures $4-8$, it is found that the maximum displacement is related to gravity-injected soil-nails for $250 \mathrm{kPa}$ force, and the maximum displacement is related to the soil-nails injected under a pressure of $200 \mathrm{kPa}$. In Table 6 , the bond strength values obtained from tensile tests are presented. The increase in bond strength under the influence of injection pressure is shown in Table 7. By examining Tables 6 and 7 it is deduced that if injection pressure is increased from zero up to $200 \mathrm{kPa}$, average bond strength increases almost $20 \%$. The increase of the bond strength under the influence of the height pressure of overburden soil is shown in Table 8. By examining Tables 6 and 8 , it is deduced that by increasing the overburden soil height from 4 to $8 \mathrm{~m}$, average bond strength increased almost $7 \%$.

\subsection{Effects of various parameters on bond strength}

To evaluate the effect of shear strength parameters of soil on bond strength, a cohesion diagram $q_{\mathrm{u}}-(c+\gamma h \tan \phi)$ was drawn. The phrase $c+\gamma h \tan \Phi$ is termed the apparent shear resistance, in which $\gamma$ is soil density $\left(\mathrm{kN} / \mathrm{m}^{3}\right), h$ is overburden height $(\mathrm{m}), c$ is soil cohesion $\left(\mathrm{kN} / \mathrm{m}^{2}\right), \Phi$ is internal friction angle (degrees) and $q_{\mathrm{u}}$ is bond resistance of soil $\left(\mathrm{kN} / \mathrm{m}^{2}\right)$. In Tables 9 and 10, the apparent shear stress and bond strength values for all samples are presented.

In Figures 9-12, diagrams of shear bond strength against apparent shear stress for gravity-injected soil-nails and

Table 5. Specification of pull-out test for a sample nail (Pasdaran site)

\begin{tabular}{|c|c|c|c|c|c|}
\hline \multicolumn{2}{|l|}{ Nail feature } & \multicolumn{4}{|c|}{ Specifications of pull-out test } \\
\hline Borehole length & $4 \mathrm{~m}$ & Load: kN & Hold: $\min$ & Gauge & Movement: $\mathrm{mm}$ \\
\hline Drilling rod diameter & $95 \mathrm{~mm}$ & 0 & 10 & $11 \cdot 38$ & 0 \\
\hline Borehole diameter & 110 & 50 & 10 & $16 \cdot 41$ & $0 \cdot 28$ \\
\hline \multirow[t]{2}{*}{ Non-bond length } & $100 \mathrm{~cm}$ & 100 & 10 & 20.69 & $0 \cdot 38$ \\
\hline & & 150 & 10 & $22 \cdot 17$ & $0 \cdot 4$ \\
\hline Unbond length & $4 \mathrm{~m}$ & 200 & 10 & $24 \cdot 42$ & 0.43 \\
\hline Injection pressure & Gravity & 250 & 10 & $25 \cdot 02$ & 0.42 \\
\hline Bar number & $\Phi 40$ & 300 & 10 & $26 \cdot 74$ & 0.44 \\
\hline Water/cement ratio & 0.4 & 350 & 10 & $28 \cdot 32$ & $1 \cdot 1$ \\
\hline Elevation from edge of wall & 8 & 400 & 10 & $30 \cdot 56$ & 0.93 \\
\hline Fail load: kN & & & & 450 & \\
\hline Bond strength: $\mathrm{kPa}$ & & & & $477 \cdot 7$ & \\
\hline
\end{tabular}




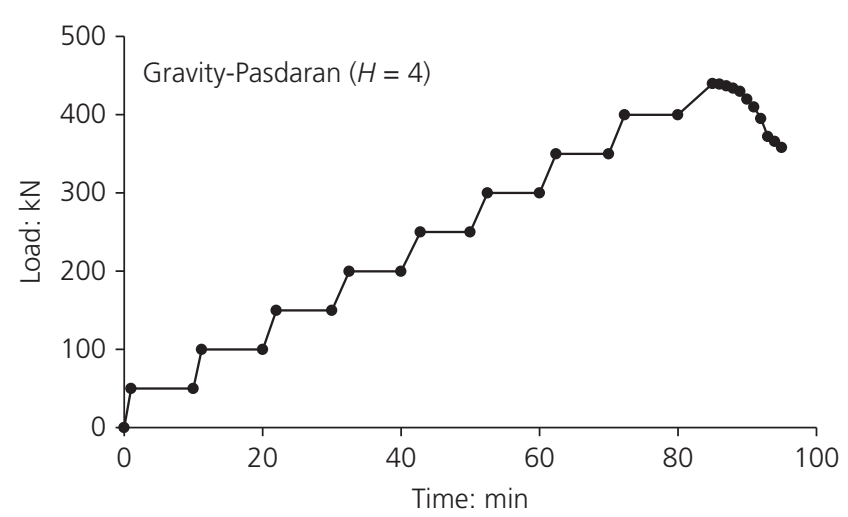

Figure 3. Load-time sample curve in tests of this research

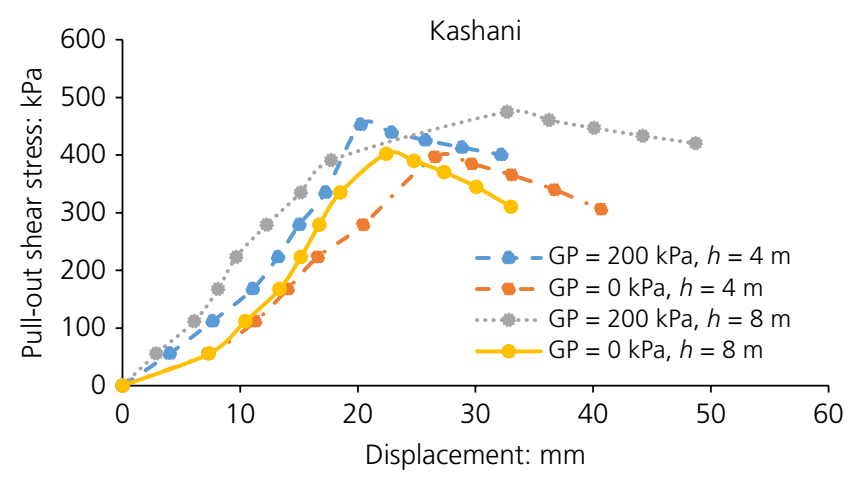

Figure 4. Diagram of shear stress plotted against displacement (Kashani site)

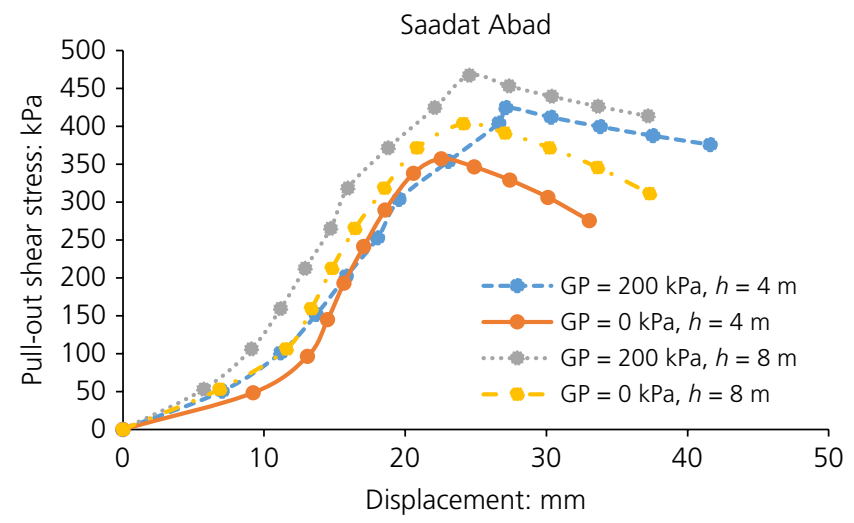

Figure 5. Diagram of shear stress against displacement (Saadat Abad site)

$200 \mathrm{kPa}$ injection pressure soil-nails at two different depths are drawn. As can be seen, in the gravity and under-pressure states, bond strength has a linear relationship with apparent stress. In Table 11, the equation and standard deviation are shown where $X$ is the apparent shear stress. By examining the values of standard deviation, the authors found that the standard deviation of the current equation for gravity-injected soilnails has good agreement with values obtained from field

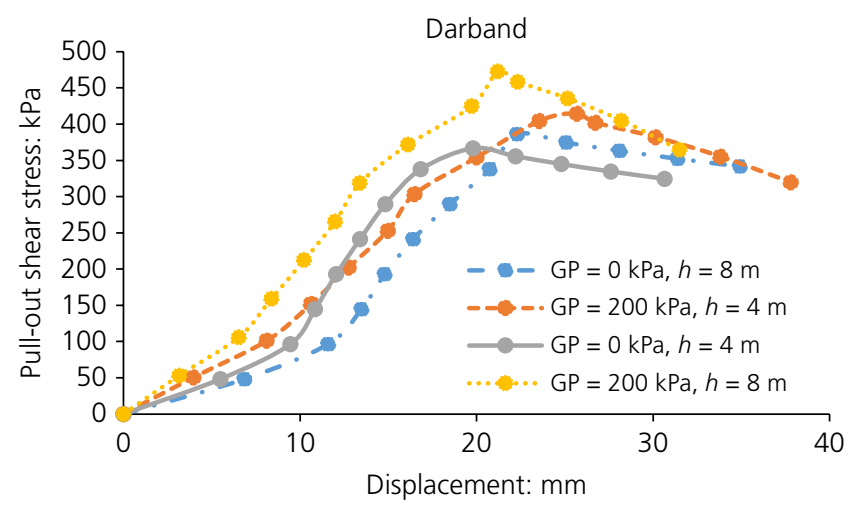

Figure 6. Diagram of shear stress against displacement (Darband site)

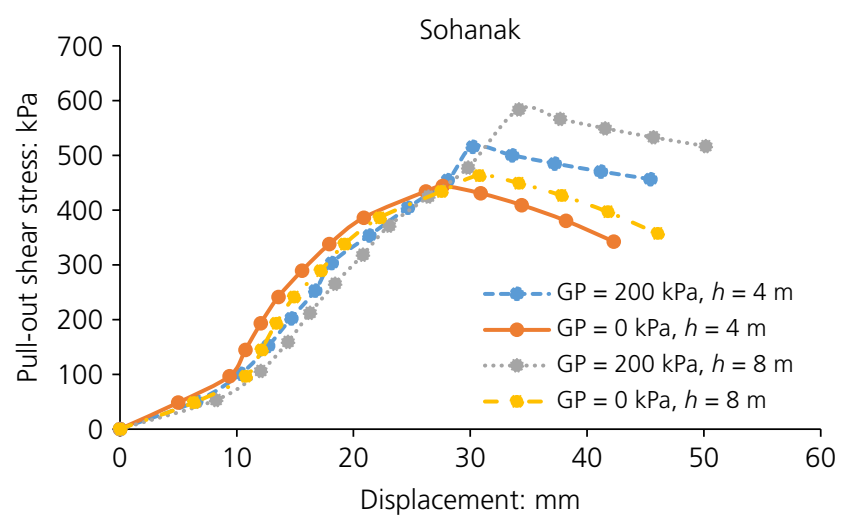

Figure 7. Diagram of shear stress against displacement (Sohanak site)

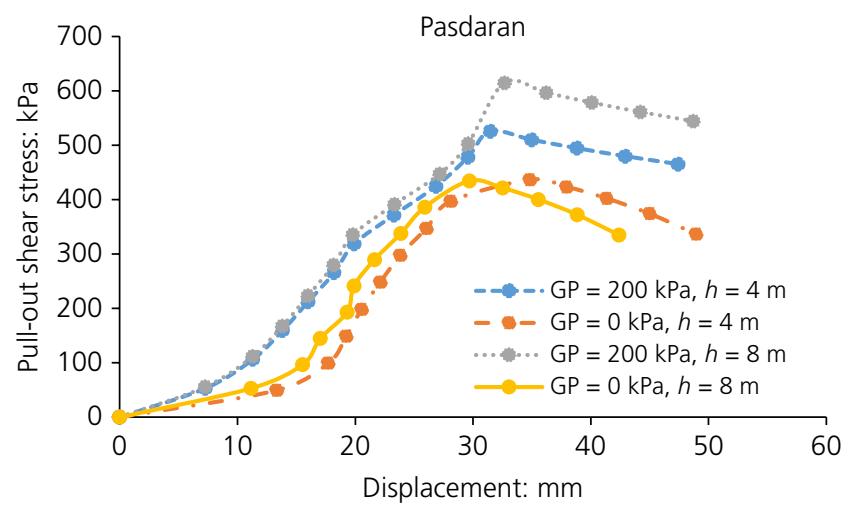

Figure 8. Diagram of shear stress against displacement (Pasdaran site)

experiments. In general, for similar soil samples having an apparent shear stress, bond strength can be determined using these equations for heights of 4 and $8 \mathrm{~m}$. By increasing injection pressure from 0 to $200 \mathrm{kPa}$, slope and $Y$ intercept values for each of the equations increased, which could be due to the influence of injection pressure on bond strength. 
Table 6. Bond strength values obtained from tensile test

\begin{tabular}{|c|c|c|c|c|}
\hline \multirow[b]{3}{*}{ Site name } & \multicolumn{4}{|c|}{ Soil-nail specifications and injection conditions } \\
\hline & \multicolumn{2}{|c|}{$H=4 \mathrm{~m}$} & \multicolumn{2}{|c|}{$H=8 \mathrm{~m}$} \\
\hline & $P=200 \mathrm{kPa}: \mathrm{kPa}$ & Gravity: kPa & $P=200 \mathrm{kPa}: \mathrm{kPa}$ & Gravity: $\mathrm{kPa}$ \\
\hline Saadat Abad & 424 & 357 & 467 & 382 \\
\hline Kashani & 452 & 396 & 474 & 402 \\
\hline Sohanak & 515 & 443 & 583 & 463 \\
\hline Pasdaran & 525 & 436 & 614 & 434 \\
\hline Darband & 414 & 366 & 472 & 386 \\
\hline
\end{tabular}

Table 7. Increase of bond strength under the influence of injection pressure

\begin{tabular}{lcc} 
& \multicolumn{2}{c}{ Increase of bond strength: \% } \\
\cline { 2 - 3 } Site name & $H=4 \mathrm{~m}$ & $\boldsymbol{H}=\mathbf{8} \mathrm{m}$ \\
Saadat Abad & 18 & 27 \\
Kashani & 14 & 19 \\
Sohanak & 16 & 25 \\
Pasdaran & 20 & 28 \\
Darband & 13 & 15
\end{tabular}

Table 8. Increase of bond strength under the influence of overburden soil height

\begin{tabular}{lcc} 
& \multicolumn{2}{c}{ Increase of bond strength: \% } \\
\cline { 2 - 3 } Site name & $(\mathrm{GP}=\mathbf{0} \mathrm{kPa})$ & $(\mathrm{GP}=200 \mathrm{kPa})$ \\
\hline Saadat Abad & $2 \cdot 5$ & 10 \\
Kashani & 1.5 & 5 \\
Sohanak & 4.5 & 12 \\
Pasdaran & $8 \cdot 6$ & 14 \\
Darband & $5 \cdot 3$ & 8 \\
\hline
\end{tabular}

\section{Comparison of the results of this study with the results of other researchers}

In this section, the results of this study are compared with the results of other researchers and valid reports such as the Elias and Juran (1991) and Lazarte et al. (2003).

- The results of this study show that, by increasing the time at each stage, the value of force increases, and after achieving a maximum the value of force decreases. This peak point is defined as the bond strength. This issue was experimentally examined by researchers such as $\mathrm{Su}$ et al. (2008), Yin and Zhou (2009) and Zhou et al. (2007), and they obtained similar results.

- The results of this research show that, by increasing the pressure up to $200 \mathrm{kPa}$, bond strength is increased about $20 \%$. This issue was studied by researchers such as Elias and Juran (1991). These researchers found that, by increasing the injection pressure up to $350 \mathrm{kPa}$, bond strength increased up to double. Other researchers such as Yin et al. (2012), Zhou et al. (2007) and Zhou et al. (2010)
Table 9. Numerical values of pull-out resistance at five different sites for depth of $8 \mathrm{~m}$

\begin{tabular}{lccc}
$\begin{array}{l}\text { Site } \\
\text { name }\end{array}$ & $\begin{array}{c}\text { Bond strength } \\
\text { (under pressure } \\
\text { 200 kPa) }\end{array}$ & $\begin{array}{c}\text { Cohesion } \\
\text { strength } \\
\text { (gravity state) }\end{array}$ & $\begin{array}{c}\mathbf{C}+\boldsymbol{\gamma h} \\
\text { (tan } \mathbf{\Phi )}\end{array}$ \\
\hline Saadat Abad & 467 & 366 & 111.94 \\
Niavaran & 472 & 386 & 124.39 \\
Kashani & 478 & 401 & 143.26 \\
Pasdaran & 614 & 500 & 170.00 \\
Sohanak & 583 & 463 & 153.00 \\
& & &
\end{tabular}

Table 10. Numerical values of pull-out resistance at five different sites for depth of $4 \mathrm{~m}$

\begin{tabular}{|c|c|c|c|}
\hline Site name & $\begin{array}{l}\text { Bond strength } \\
\text { (under pressure } \\
200 \mathrm{kPa} \text { ) }\end{array}$ & $\begin{array}{c}\text { Cohesion } \\
\text { strength } \\
\text { (gravity state) }\end{array}$ & $\begin{array}{c}\text { Apparent } \\
\text { shear stress } \\
C+\gamma h(\tan \Phi)\end{array}$ \\
\hline Saadat Abad & 424 & 357 & 59.47 \\
\hline Niavaran & 414 & 366 & $66 \cdot 70$ \\
\hline Kashani & 452 & 396 & 77.63 \\
\hline Pasdaran & 525 & 436 & $82 \cdot 00$ \\
\hline Sohanak & 515 & 443 & $100 \cdot 95$ \\
\hline
\end{tabular}

studied the effect of the injection pressure and all of them concluded that the bond strength increases by increasing injection pressure.

Zhou et al. (2010) found that, by increasing the injection pressure from 250 to $350 \mathrm{kPa}$, the bond strength would increase about $80 \%$.Yin and Zhou (2009) concluded that the effect of injection pressure on the shear strength in pressures $<130 \mathrm{kPa}$ is almost negligible, but by increasing injection pressure up to $250 \mathrm{kPa}$ the cohesion strength increases almost $25 \%$.

- The results of this study show that, according to the field tests, by changing overburden height up to $4 \mathrm{~m}$, the bond strength is not much changed; however, researchers such as $\mathrm{Su}$ et al. (2007) investigated the simultaneous effects of the injection pressure and overburden. The results of these researchers showed that by increasing overburden pressure the bond strength of soil-nails increases, but in the gravity-injected soil-nails the bond strength does not increase owing to a release of stress while drilling. 


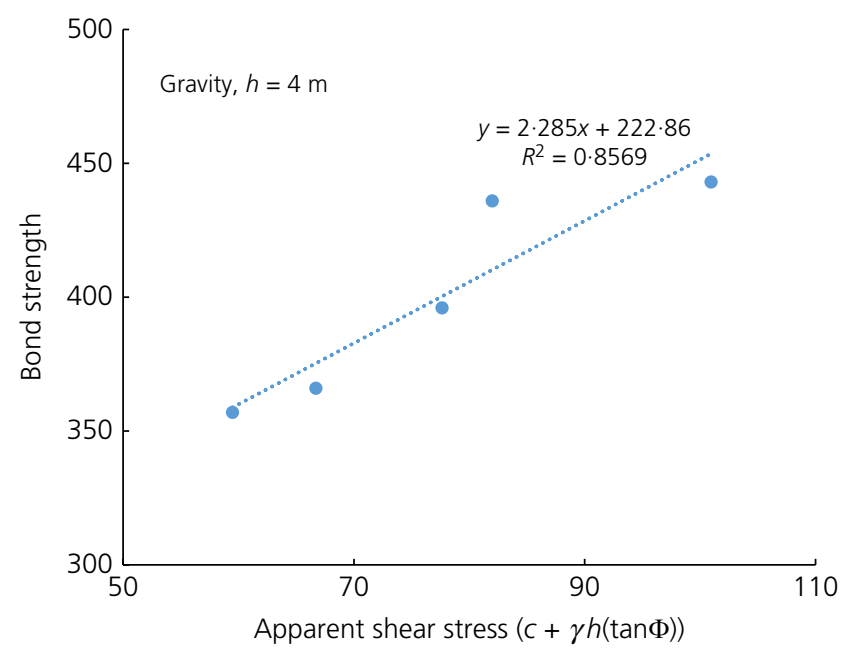

Figure 9. The relationship between shear strength parameters and bond strength ( $h=4 \mathrm{~m}$, gravity)

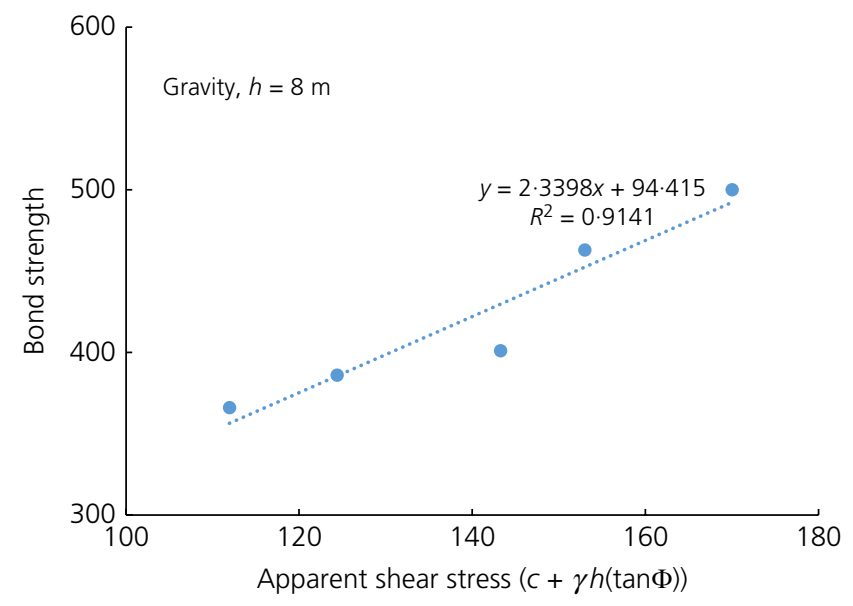

Figure 10. The relationship between shear strength parameters and bond strength ( $h=8 \mathrm{~m}$, gravity)

\section{Conclusions}

In this study, a series of field tests on five soil samples was carried out to determine the effects of overburden pressure, injection pressure and basic characteristics of the soil on nail pull-out strength. The results obtained can be summarised as follows.

- By increasing the steps at each stage the value of the force increases and, after achieving the maximum force, the value of the force decreases.

- By increasing the injection pressure up to $200 \mathrm{kPa}$, the average bond strength increases about $20 \%$.

However, when increasing the depth (overburden) from 4 to $8 \mathrm{~m}$ the bond strength increment is almost negligible (about 7\%).

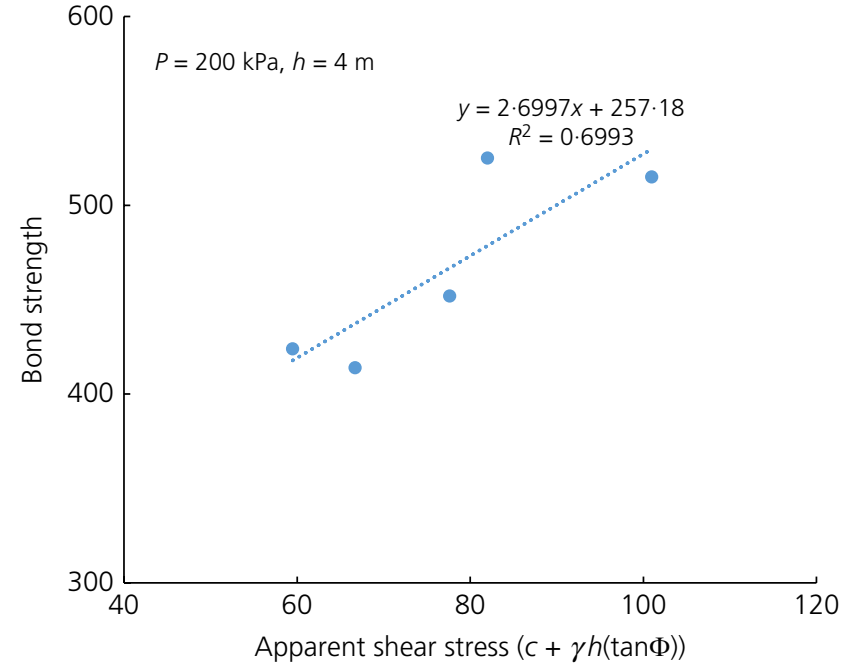

Figure 11. The relationship between shear strength parameters and bond strength $(h=4 \mathrm{~m}, p=200 \mathrm{kPa})$

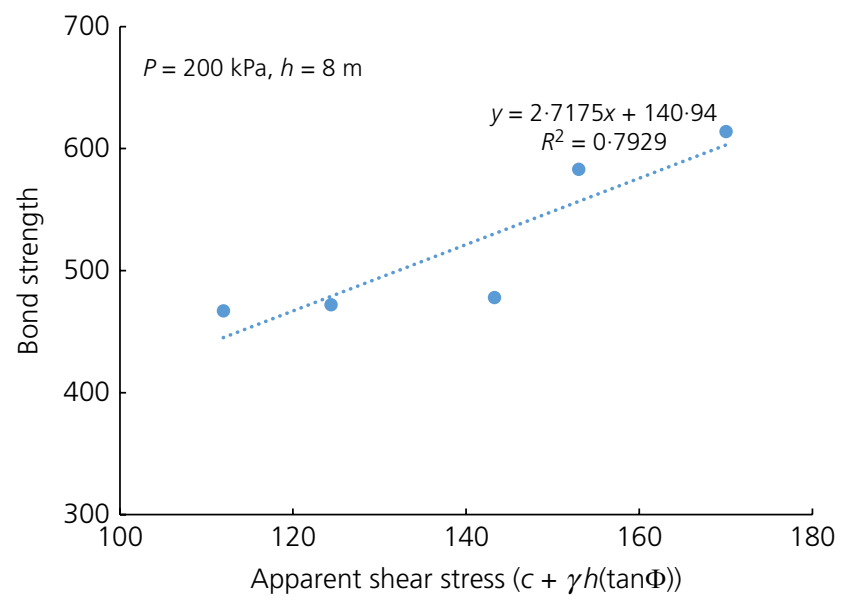

Figure 12. The relationship between shear strength parameters and bond strength $(h=8 \mathrm{~m}, p=200 \mathrm{kPa})$

Table 11. Equation and standard deviation of relationships between bond strength and apparent shear stress

\begin{tabular}{lccc|}
$\begin{array}{l}\text { Site } \\
\text { name }\end{array}$ & $\begin{array}{c}\text { Bond strength } \\
\text { (under pressure } \\
\text { 200 kPa) }\end{array}$ & $\begin{array}{c}\text { Cohesion } \\
\text { strength } \\
\text { (gravity state) }\end{array}$ & $\begin{array}{c}\text { Apparent } \\
\text { shear stress } \\
\text { C+ } \boldsymbol{\text { jh }} \text { (tan } \boldsymbol{\Phi} \text { ) }\end{array}$ \\
\hline Saadat Abad & 424 & 357 & 59.47 \\
Niavaran & 414 & 366 & 66.70 \\
Kashani & 452 & 396 & 77.63 \\
Pasdaran & 525 & 436 & 82.00 \\
Sohanak & 515 & 443 & 100.95 \\
\hline
\end{tabular}

- Maximum displacement occurs for a force of $250 \mathrm{kPa}$ related to the gravity-injected soil-nails, and maximum displacement occurs related to soil-nails under a pressure of $200 \mathrm{kPa}$. 
For all soil-nails the apparent shear stress has a linear relationship with bond strength, so for similar soil samples undergoing apparent shear stress, bond strength can be determined.

- In cemented soils, displacement of soil-nails under pull-out testing is the same for both gravity and pressure injection modes.

\section{REFERENCES}

ASTM (1990) D422-63: Standard test method for particle-size analysis, ASTM International, West Conshohocken, PA, USA

Chu LM and Yin JH (2005) Comparison of interface shear strength of soil nails measured by direct shear box tests and pullout tests. Journal of Geotechnical and Geoenvironmental Engineering 131(9): 1097-1107.

Elias V and Juran I (1991) Soil Nailing for Stabilization of Highway Slopes and Excavations. Federal Highway Administration, Washington, DC, USA, Publication FHWA-RD-89-198.

Junaideen SM, Tham LG, Law KT, Lee CF and Yue ZQ (2004) Laboratory study of soil-nail interaction in loose completely decomposed granite. Canadian Geotechnical Journal 41(2): 274-286.

Lazarte CA, Elias V, Espinoza RD and Sabatini PJ (2003) Soil Nail Walls. Geotechnical Engineering Circular No. 7. Federal Highway Administration, Washington, DC, USA, Publication FHWA-IF03-017.

Schlosser F (1982) Behaviour and design of soil nailing. In Proceeding on Recent Developments in Ground Improvement Techniques, Bangkok, Thailand (Balasubramaniam AS, Chandra S, Bergado DT, Younger JS and Prinzl F (eds)). Balkema, Rotterdam, the Netherlands, pp. 399-413.
Su LJ (2006) Laboratory Pullout Testing Study on Soil Nails in Compacted Completely Decomposed Granite Fill. PhD thesis, Hong Kong Polytechnic University, Puk Fu Lam, Hong Kong.

Su LJ, Chan TCF, Shiu YK, Cheung T and Yin JH (2007) Influence of degree of saturation on soil nail pull-out resistance in compacted completely decomposed granite fill. Canadian Geotechnical Journal 44(11): 1314-1328.

Su LJ, Chan TCF, Yin JH, Shiu YK and Chiu SL (2008) Influence of overburden pressure on soil-nail pullout resistance in a compacted fill. Journal of Geotechnical and Geoenvironmental Engineering 134(9): 1339-1347.

Ukas (United Kingdom Accreditation Service) (2006) Calibration of Weighing Machines, LAB143904, 4th edn. UKAS, Staines-upon-Thames, UK.

Yin JH and Su LJ (2006) An innovative laboratory box for testing nail pullout resistance in soil. ASTM Geotechnical Testing Journal 29(6): 451-461.

Yin JH and Zhou WH (2009) Influence of grouting pressure and overburden stress on the interface resistance of a soil nail. Journal of Geotechnical and Geoenvironmental Engineering 135(9): $1198-1208$.

Yin J, Hua C and Zhou W (2012) Simplified analytical method for calculating the maximum shear stress of nail-soil interface. International Journal of Geomechanics 12(3): 309-317.

Zhou WH, Yin JH, Zhu HH and Hong CY (2007) Study on the effects of grouting pressure and overburden pressure on the pullout resistance of soil nails. Proceedings of the 60th Canadian Geotechnical Conference \& 8th joint CGS/IAH-CNC Groundwater Conference, Ottawa, ON, Canada, pp. 985-990.

Zhou WH, Yin JH, Zhu HH and Hong CY (2010) Effects of overburden stress and grouting pressure on soil nail pullout resistance. Proceedings of the 17th Southeast Asian Geotechnical Conference, Taipei, Taiwan, pp. 248-251.

\section{How can you contribute?}

To discuss this paper, please email up to 500 words to the editor at journals@ice.org.uk. Your contribution will be forwarded to the author(s) for a reply and, if considered appropriate by the editorial board, it will be published as discussion in a future issue of the journal.

Proceedings journals rely entirely on contributions from the civil engineering profession (and allied disciplines). Information about how to submit your paper online is available at www.icevirtuallibrary.com/page/authors, where you will also find detailed author guidelines. 